\title{
DEMENTIA AND MENTAL HEALTH SERVICES FOR OLDER PEOPLE IN THE LANCASTER DISTRICT
}

\author{
YP Shukla, Clinical Assistant in Psychiatry \\ Royal Lancaster Infirmary
}

\section{INTRODUCTION}

Specialist psychiatric services for the elderly have been developed since the mid-1960s. The importance of these services has increased due to an increased number of elderly people, the high prevalence and incidence of psychiatric disorder in late life, the association of psychiatric disorder with physical disease and the social and economic circumstances of late life.

Nationally, over $37 \%$ of first psychiatric admissions and $33 \%$ of readmissions occur in patients over 65 years of age and where an active psychiatric service for older people develops this proportion is likely to increase.

There is a need for understanding and liaison between medical specialists, social workers and other professions such as lawyers and voluntary organisations, which relate to the elderly. We would like these services to be communityorientated, offering easy access to psychiatric expertise for people in their own homes. Services aim to facilitate referral, usually from general practitioners (GPs) or other hospital specialists for early diagnosis and treatment, followed by effective follow-up and support, which may be necessary for the rest of the patient's life.

Government standards and the recommendations of the Royal College of Psychiatrists for mental health services for the elderly are outlined and compared with our local facilities.

Dementia is an organic mental disorder due to disease of the brain, chronic or progressive in nature, characterised by loss of memory (initially short-term, then long-term), disturbance of multiple higher cortical functions (including orientation, comprehension, learning capacity, thinking, intellect, judgement, language [dysphasia]), apraxia (inability to perform learned movement where there is no sensory or motor deficit) and agnosia (inability to understand or recognise objects and forms in the presence of normal peripheral sensation) in a clear consciousness.

There is also deterioration in emotional control, social behaviour, motivation, activity of daily living (ADL), ie washing and dressing and personal care, causing difficulties in maintaining an independent lifestyle and resulting in a state of confusion, disorientation and unusual or distressing behaviour which can put the patient and/or others at risk. Sleep is often disturbed, with nocturnal wandering, such as wandering down the street in night-clothes.

\section{DEMOGRAPHY}

About $16 \%$ (eight million) of the UK population are over 65 years old, and 700,000 people suffer from dementia, including 17,000 pre-senile dementia. Alzheimer's disease accounts for approximately $55 \%$ of dementia and has an insidious onset and, usually, an absence of neurological signs of focal brain damage.

The characteristic changes in the brain show a marked reduction in numbers of neurones, particularly in the hippocampus, temporoparietal and frontal cortex, appearance of neurofibrillary tangles and amyloid or senile plaques, which are larger and greater in numbers than in the normal ageing process. Neurochemical changes include a marked reduction in the enzyme choline acelyltransferase and in acetylocholine itself. Both animal and clinical studies have shown that cholinergic pathways play a vital role in the process of learning and memory. The degeneration of cholinergic neurones in the forebrain is believed to be responsible for at least some of the cognitive deficit.

Vascular dementia accounts for approximately $20 \%$ of dementia. It is dementia resulting from vascular disease, is abrupt in onset and shows stepwise deterioration with a history of transient ischaemic attacks, with impairment of consciousness and focal neurological signs and symptoms (ie fleeting paresis, visual loss).

Dementia may follow a succession of acute cerebrovascular accidents or a major stroke.

Lewybody dementia accounts for about $15 \%$ of sufferers and is characterised by fluctuating cognition with variations in attention and alertness, visual hallucinations, repeated falls, features of Parkinsonism and neuroleptic sensitivity.

Frontal lobe dementia is characterised by personality changes, early loss of insight, nonfluent aphasia with wellpreserved spatial orientation.

Pick's disease is a progressive dementia, usually occurring in middle life, characterised by slow changes in character and social deterioration, followed by impairment of intellect, memory and language function with apathy and euphoria (occasionally extra pyramidal phenomena).

Pick's disease and frontal lobe dementia account for approximately $5 \%$ of patients.

Creutzfeldt-Jacob disease (CJD) is a progressive dementia with extensive neurological signs, progressive spastic 
paralysis of the limbs with tremor, rigidity and choreoathetoid movements and has characteristic (triphasic) electroencephalogram.

New Variant CJD is a new form which is a rare frontal brain disorder unique to the UK and is almost certainly caused by exposure to BSE, a prion disease found in cattle. The majority of cases have been reported in young people. Initially patients present with psychiatric manifestations such as anxiety and depression, and behavioural changes, and may report persistent pain and odd sensations in the face and limbs. After some weeks or months disturbance of gait and sudden jerky movements can be seen and progressive dementia becomes more marked, leading to loss of the ability to move or speak. Death occurs within a year of the onset of symptoms.

Other dementias, ie alcohol, brain tumour, normal pressure hydrocephalus (dementia, urinary incontinence and gait disturbances), HIV, new variant CJD etc, account for approximately $5 \%$ of cases.

There is no single gene for Alzheimer's disease but genetic factors are responsible for the disease in a small number of families. Some evidence, however, suggests that for early onset Alzheimer's disease there is a genetic fault on chromosome 21 in a gene called Amyloid Precursor Protein or App, that affects production of the protein Amyloid. This protein has been associated with Alzheimer's disease when it builds up in the brain.

Some families carry a fault on chromosome 14 (Presenilin1), while some have a fault on chromosome 1 (Presenilin-2). All these genetic faults are associated with early onset of Alzheimer's disease, usually between the ages of 35 and 60 . In late-onset Alzheimer's disease, the link is with a protein called Apolipoprotein (ApoE). It comes in three forms known as $A_{p o E}, A_{p o E}$ and $\mathrm{ApoE}_{4}$. We have two copies of genes which may be the same as or different to each other, out of which $\mathrm{ApoE}_{4}$ is associated with higher risk (up to four times greater), while $\mathrm{ApoE}_{2}$ is the gene least associated with Alzheimer's disease.

The gene for the $\mathrm{K}$ variant of Butyrylcholinesterase (BCHE-K) interacts with ApoE, a gene to greatly increase the risk of developing Alzheimer's disease. This has implications for future drug developments and in the identification of those individuals most likely to benefit from current drugs.

Acetylcholinesterase inhibitors prevent Acetylcholinesterase from working and hence Acetylcholine, which carries the chemical messages, is able to remain longer within nerve cells and there is more chance of the Acetylcholine being passed on to the next nerve cell and transmitting the message.

A number of Acetylcholinesterase inhibitor drugs are available, ie donepezil hydrochloride (Aricept), rivastigmine (Execon; shorter half-life than doneprezil), metrifonate (less liver toxicity) and galanthamine. Tacrine was prescribed in the USA but later found to produce marked side effects including hepatictoxicity.

A number of hypotheses have been explored regarding possible risk factors for Alzheimer's disease, such as family history of dementia, Parkinson's disease or Down's syndrome. Others are a history of head trauma with loss of consciousness, hypothyroidism, exposure to aluminium (in water, renal dialysis, antacids, antiperspirants), mercury (brain content of mercury is increased in Alzheimer's disease - mercury can escape from dental amalgam, hence mercury fillings are not advisable), solvents such as benzene and toluene. Factors such as smoking, drinking wine (mildmoderate), vitamin supplements, anti-inflammatory drugs and hormone replacement therapy have been suggested as reducing the risk of developing dementia.

High levels of a key protein have been found in the blood of sufferers of Alzheimer's disease. Researchers at the University of British Columbia in Vancouver and Chiba University, Japan, have found that people with Alzheimer's disease have an abnormally high level of the protein p97 in their blood. The levels were higher in the more advanced cases of Alzheimer's disease, leading researchers to believe that in future a simple blood test may enable us to identify potential sufferers before a significant clinical picture develops. The test could also be used to monitor response to medication.

Other research found elevated serum total Homocystenine levels in patients with Alzheimer's disease and it appears that these may be a consequence of the disease

Studies have reported an association between lower education and Alzheimer's disease. Subjects with a high level of education have increased synaptic density and, therefore, increased 'brain reserve'. These people generally have greater cerebral blood flow. This may lead to test failure to detect cognitive impairment so that diagnosis needs to be supported by evidence of decline in social and functional capabilities assessed on an individual basis.

\section{Critical flicker fusion test (CFFT)}

CFFT has been shown to be a valid and reliable measure of CNS function. The critical flicker fusion test has potential for use in the early detection of Alzheimer's disease. It meets many of the criteria for an 'ideal' test in that it is quick, noninvasive, simple for patient and tester and requires minimal training. It is reliable, valid, objective, has no educational or cultural bias and is sensitive only to changes due to the disease process, not to changes due to age.

The test involves exposing the patient to a flickering light, the rate of flicker being adjustable by ascending or descending until the light is perceived to stop/start flickering.

Patients with Alzheimer's disease were found to have significantly lower CFFT and descending scores compared with normal elderly subjects. In the patient group, descending thresholds were significantly lower than ascending thresholds, but in patients responding to anticholinesterase drugs, this was reversed to the normal situation as found in non-dementing elderly, with the change in the CFFT occurring before the clinical response.

\section{Prevalence of dementia}

Risk increases with age. The chances of being affected are shown in Table 1.

\begin{tabular}{|l|c|}
\hline under 65 years & 1 in 1000 \\
\hline $65-70$ & 1 in 50 \\
\hline $70-80$ & 1 in 20 \\
\hline over 80 & 1 in 5 \\
\hline over 95 & 1 in 2 \\
\hline
\end{tabular}

Table 1 Chances of developing Alzheimers disease at different ages 
Figures for the Lancaster district taken from the city council census of 1991 are given in Table 2. Present figures are likely to be greater than these as those in the table are now eight years old and life expectancy is steadily increasing, so the disease will become more of a problem as the new millennium approaches. A recent local research project identified 32 early onset dementia sufferers in Lancaster and Morecambe, 21 male and 11 female.

\begin{tabular}{|ll|c|c|}
\hline MALE & & PREVALENCE & DEMENTIA \\
\hline $65-69$ & 3049 & $2 \%$ & $=61$ \\
\hline $70-79$ & 4678 & $5 \%$ & $=234$ \\
\hline $80-84$ & 1121 & \multirow{2}{*nnn}{$20 \%$} & $=402$ \\
\cline { 1 - 2 } over 85 & 897 & & \\
\cline { 1 - 2 } TOTAL & 9745 & 697 & $=70$ \\
\hline FEMALE & & & $=315$ \\
\hline $65-69$ & 3479 & $2 \%$ & $=975$ \\
\hline $70-79$ & 6306 & $5 \%$ & 1360 \\
\hline $80-84$ & 2362 & $20 \%$ & \\
\hline over 85 & 2512 & & \\
\cline { 1 - 2 } TOTAL & $\mathbf{1 4 6 5 9}$ & & \\
\hline
\end{tabular}

Table 2 Prevalence of dementia in the Lancaster district (from Lancaster City Council census, 1991)

The government standard puts emphasis on the importance of primary care and suggests that the role of the GP should be to detect early signs of mental health problems in an elderly person and identify any risk of depression or suicide when an elderly person has major life events such as retirement, bereavement, discharge from general hospital or having physical illness.

Early detection of hearing or visual impairment in the elderly can reduce the incidence of isolation and paranoid symptoms. In the same way, early detection of cognitive impairment for potential reversible causes (B12 deficiency, thyroid disorder, hypercalcaemia, uraemia) can help functional ability. Also helpful in detecting early onset of Alzheimer's disease are acetylcholinesterase inhibitors which have some role in slowing down deterioration and/or improving activity of daily living in some cases. Prescribing anti-clotting drugs such as aspirin may help in reducing further damage in vascular dementia. A review of medication should be done because polypharmacy increases the risk of side effects, eg constipation from enhanced anti-cholinergic side effects of a combination of neuroleptics and tricyclic anti-depressants. Smaller doses may be helpful in reducing toxicity caused by impaired hepatic/renal function.

The Royal College of Psychiatrists recommends early referral by the GP and the consultant psychiatrist should also respond as early as possible - on the same day in the case of a crisis. Ideally, an assessment should be undertaken by the consultant or senior doctor in the patient's home, with or without another member of the multi-disciplinary team. Collateral history should be obtained from a relative or carer, identifying the main problems, and discussion should start regarding planning future care, the identification of a key worker and the formulation of a comprehensive care plan.

Organisation of psychiatric services for people over 65 years

The old age psychiatric services should serve a defined local population of no greater than 40,000 elderly people. Table 3 compares Lancaster district's old age psychiatric service with the recommendations of the Royal College of Psychiatrists.

Social worker input is very important and there should be access to speech therapy. The report further recommends an increase in staffing if facilities are on several sites, as ours are (Lancaster Moor Hospital, Royal Lancaster Infirmary and Queen Victoria Hospital, Morecambe).

Thus psychiatric services for the elderly in the Lancaster District are community-based and continuing care units will be transferred from Lancaster Moor Hospital to the following units:

\section{Lancaster: Ashton Road \\ Morecambe: Altham Road \\ Heysham: Trumacar}

These will be purpose-built, with a bedroom for each resident with en-suite facilities to enable maximum levels of privacy and dignity. There will be input from physiotherapists and occupational therapists, regular visits by consultant psychiatrists and close working links with the local branch of the Alzheimer's Disease Society, which will be based in the Morecambe Unit.

We are in the process of developing our service by establishing two community health teams based in the Lancaster and Heysham units. These teams will be multidisciplinary and will enable us to streamline our referral processes and response times.

It is also hoped to develop a Memory Clinic, staffed by a multi-disciplinary team.

Currently staff, carers and voluntary organisations are working together towards ensuring that the transition from a traditional psychiatric hospital base to an integrated community service will take place as smoothly and effectively as possible, to enable us to meet our mission statement, which is:

"To deliver a comprehensive range of high quality services to people in a variety of settings so as to ensure their individual needs are identified and met in appropriate and valued ways, and for the user of the service to be central to the activity".

\section{BIBLIOGRAPHY}

Royal College of Psychiatrists Council Report CR49 October 1995

\section{Royal College of Psychiatrists Council Report CR36}

Mental Health of the Nation: A report of residents working group Royal College of Psychiatrists Council Report CR16

Royal College of Psychiatrists Consensus statement on the assessment and investigation of an elderly person with suspected cognitive impairment by a specialist old age psychiatry service. Council Report CR49 October 1995

\section{ICD10 Classification of mental and behavioural disorder}

\section{Alzheimer's Disease Society handouts}

Healix Update information 


\begin{tabular}{|c|c|}
\hline ROYAL COLLEGE RECOMMENDATIONS & LANCASTER DISTRICT \\
\hline population 40,000 elderly over 65 years & population $25,000+$ \\
\hline $\begin{array}{l}\text { acute beds } 1 \mathrm{bed} / 1000 \text { preferable on general hospital site for } \\
\text { investigation/treatment/rehabilitation } \\
\text { if they provide service for pre-senile dementia, chronic } \\
\text { psychosis/neurosis then } 2 \text { beds } / 1000\end{array}$ & $\begin{array}{l}\text { admission/assessment wards } \\
\text { Thurnham Unit (Ridge Lea Hospital) mixed } \\
\text { functional/organic } \\
\text { Gaskell Unit (Royal Lancaster Infirmary) organic }\end{array}$ \\
\hline for continuing care and respite admission $2.5-3$ beds $/ 1000$ & $\begin{array}{l}\text { Lancaster Unit } 28 \text { beds } \\
\text { Morecambe Unit } 24 \text { beds } \\
\text { Heysham Unit } 28 \text { beds } \\
\text { These units are due to move from the Lancaster Moor site to } \\
\text { community bases in November } 1999\end{array}$ \\
\hline $\begin{array}{l}\text { day hospitals for assessment/investigation/ treatment usually best } \\
\text { sited near acute wards on DGH site } \\
\text { rehabilitation and support day hospital better placed within } \\
\text { community as small units of } 20-30 \text { places } \\
\text { total number required } 2-3 \text { places } / 1000 \text { (out of which } 1 / 3 \text { for } \\
\text { functional illness and } 2 / 3 \text { for organic mental illness) }\end{array}$ & $\begin{array}{lr}\text { Woodlands View day hospital (Lancaster) } & 20 \\
\text { Queen Victoria day hospital (Morecambe) } & 20 \\
\text { Euston Road day hospital (Morecambe) } & 20 \\
\text { Gaskell Unit (organic) } & 4 \\
\text { Thurnham Unit } & 4 \\
& \\
\text { other day care services through Social Services, which include: } \\
\text { Sulyard Street } & 40 \\
\text { Cartmel House (Morecambe) } & 60 \\
\text { St Martin's Thursday afternoon through Alzheimer's Disease } & \\
\text { Society } & \\
\text { Age Concern (Morecambe, } 5 \text { days/week) } & \\
3 \text { luncheon clubs } & \\
\text { Evergreen Club (Ryelands) lunch once/week } & \\
\text { drop-in centres at Scotforth and Skerton } & \text { Relief Care Service - support for carers, } \\
\text { provided by Alzheimer's Disease Society } & \\
\text { counselling and information resource through } & \end{array}$ \\
\hline $\begin{array}{l}\text { outpatient clinic ideally should be based at general hospital site to } \\
\text { allow close liaison with general physician and for special } \\
\text { investigations (ECG, EEG, CT brain scan) }\end{array}$ & $\begin{array}{l}\text { at present this facility is not available, hence outpatient clinic at } \\
\text { Ridge Lea and Queen Victoria Hospitals }\end{array}$ \\
\hline $\begin{array}{l}\text { follow-up should preferably be in patient's home or GP's surgery, to } \\
\text { avoid bringing elderly persons to outpatient clinic } \\
\text { referral expected about } 250 / 10,000 \text { pa }\end{array}$ & $\begin{array}{l}\text { very time-consuming } \\
\text { we expect } 650+\text { pa }\end{array}$ \\
\hline $\begin{array}{r}\text { Royal College of Psy } \\
\text { CPN (eld } \\
\text { occupational th } \\
\text { physiotherapist and clin }\end{array}$ & $\begin{array}{l}\text { iatrists recommends: } \\
\text { y) } 1 / 5000 \\
\text { apist } 1 / 10,000 \\
\text { al pyschologist } 1 / 20,000\end{array}$ \\
\hline
\end{tabular}

Table 3 A comparison of the Lancaster district old age psychiatric service with the recommendations of the Royal College of Psychiatrists 